\title{
AROUITETURA, ORGANISMO E SISTEMA: OBSERVAÇÕES SOBRE A FILOSOFIA E SUA EXPOSIÇÃO EM SCHOPENHAUER
}

\author{
ARCHITECTURE, ORGANISM AND SYSTEM: OBSERVATIONS ON PHILOSOPHY
}

AND IIS EXPOSITION IN SCHOPENHAUER

\author{
FLAMARION CALDEIRA RAMOS ${ }^{1}$ \\ Universidade Federal do ABC (UFABC) - Brasil \\ flamarion.ramos@ufabc.edu.br
}

\begin{abstract}
RESUMO: A relação entre os quatro livros de O mundo como Vontade e Representação, isto é, entre as quatro partes da filosofia de Schopenhauer (gnosiologia, metafísica, estética e ética), tem sido uma das questões mais controversas da pesquisa sobre seu pensamento. Saber se a ética é de fato mais importante que a estética, ou se a metafísica deve ser subordinada à teoria do conhecimento, são questões que têm ocupado frequentemente os intérpretes do filósofo. Há diversas interpretações rivais sobre o modo como a filosofia de Schopenhauer deve ser lida, se como um sistema arquitetônico e linear, ou orgânico e sem subordinação de uma parte à outra, por exemplo. As afirmações do próprio autor sobre o estatuto de sua filosofia nem sempre são suficientes para dirimir as controvérsias. No presente artigo, procurarei reconstruir algumas dessas leituras e propor uma interpretação própria para o que entendo ser o sistema filosófico de Schopenhauer.
\end{abstract}

PALAVRAS-CHAVE: Sistema. Organismo. Arquitetura. Exposição. Filosofia.

ABSTRACT: The relationship between the four books of The World as Will and Representation, that is, between the four parts of Schopenhauer's philosophy (gnosiology, metaphysics, aesthetics, and ethics), has been one of the most controversial questions within the Schopenhauer-Forschung. To know whether ethics is more important than aesthetics, or whether metaphysics should be subordinated to the theory of knowledge, are matters that have often occupied the interpreters of the philosopher. There are several competing interpretations of how Schopenhauer's philosophy is to be read, whether as an architectural and linear system, or organic and without subordination from one part to another, for example. The author's own statements about the status of his philosophy are not always sufficient to resolve the controversies. In this article, I will try to reconstruct some of these readings and propose a proper interpretation for what I understand to be Schopenhauer's philosophical system.

KEYWORDS: System. Organism. Architecture. Exposition. Philosophy.

"É igualmente mortal ao espírito ter um sistema e não ter nenhum". Friedrich Schlegel

\footnotetext{
${ }^{1}$ Professor de Ética e Filosofia Política da Universidade Federal do ABC (UFABC).
} 
Toda a discussão sobre o estatuto sistemático da filosofia de Schopenhauer parte de uma interpretação da seguinte passagem do prefácio à primeira edição ${ }^{2}$ de O Mundo como Vontade e Representação:

Um sistema de pensamentos tem sempre de possuir uma coesão arquitetônica, ou seja, uma tal em que uma parte sustenta continuamente a outra, e esta, por sua vez, não sustenta aquela, em que a pedra fundamental sustenta todas as partes, sem ser por elas sustentada; em que o topo é sustentado, sem, no entanto, sustentar. Ao contrário, um único pensamento [ein einziger Gedanke], por mais abrangente que seja, guarda a mais perfeita unidade. Se, todavia, em vista de sua comunicação, é decomposto em partes, então a coesão destas tem de ser, por sua vez, orgânica, isto é, uma tal em que cada parte tanto conserva o todo quanto é por ele conservada, nenhuma é a primeira ou a última, o todo ganha em clareza mediante cada parte, e a menor parte não pode ser plenamente compreendida sem que o todo já o tenha sido previamente. - Um livro tem de ter, entrementes, uma primeira e uma última linha; nesse sentido, permanece sempre bastante dessemelhante a um organismo, por mais que se assemelhe a este em seu conteúdo. Consequentemente, forma e estofo estarão aqui em contradição. (WWV I/MVR I, p. XXV-XXVI). ${ }^{3}$

Se nos basearmos nessa passagem e na sequência em que Schopenhauer afirma como a sua principal obra deve ser lida, teríamos que ter em vista essa primazia da metáfora do organismo em detrimento da metáfora da arquitetura para caracterizar sua filosofia e o modo como ela foi exposta. O sistema de Schopenhauer é apresentado nos quatro livros que compõe sua obra principal, $O$ Mundo como Vontade e Representação. Poderíamos dizer que cada livro tem uma unidade temática, sendo o primeiro dedicado a fornecer as bases epistemológicas da doutrina por meio de uma teoria da representação; o segundo, desenvolve o núcleo de sua metafísica, a descoberta do "mundo como vontade"; o terceiro livro apresenta a teoria das ideias - a representação para além do princípio de razão, o objeto da arte; o quarto livro apresenta a ética por meio da teoria da afirmação e da negação da vontade de viver. Todavia, como exposição de um único pensamento, a filosofia de Schopenhauer não pode apresentar-se de modo arquitetônico, como uma sequência dedutiva a partir de um único princípio, e constitui-se mais como um todo de proposições que se condicionam e se completam mutuamente. Essas proposições são compostas em pequenos grupos, de modo que o único pensamento encontra neles uma exposição particular, mas de uma maneira tal que cada grupo, enquanto parte do sistema, exponha o todo que é o desdobramento daquele único pensamento. As diferentes disciplinas que

\footnotetext{
${ }^{2}$ Schopenhauer começou a redigir sua obra principal, O Mundo como Vontade e Representação, a partir de 1814 em Dresden. A obra foi publicada em dezembro de 1818, mas com a data de 1819. Em 1844 publicou uma segunda edição contendo um segundo volume de complementos e em 1859 uma terceira edição revisada. As citações da obra de Schopenhauer serão referenciadas de acordo com as siglas adotadas para o presente dossiê. Em geral, darei preferência às traduções disponíveis em português, indicando, porém, eventuais modificações.

${ }^{3}$ Sempre citarei a obra principal de Schopenhauer segundo a tradução de Jair Barboza da Editora Unesp. Nesta passagem que constitui a base do presente artigo fiz uma pequena modificação da expressão "pensamento único" por "único pensamento". Essa terrível nuance se justifica pela má lembrança que a expressão "pensamento único" evoca, desde os anos noventa, e segue a sugestão de Paulo Licht dos Santos em sua tradução do artigo de M. Kossler, intitulado "A única intuição o único pensamento: Sobre a questão do sistema em Fichte e em Schopenhauer (2007).
} 
compõem as partes desse sistema, concebido de modo orgânico, são para Schopenhauer quatro pontos de vista de um único pensamento: "quando se levam em conta os diferentes lados desse único pensamento a ser comunicado, ele se mostra como aquilo que se nomeou seja metafísica, seja ética, seja estética. E naturalmente ele tinha de ser tudo isso, caso fosse o que, como já mencionado, o considero" (Idem, ibidem). ${ }^{4}$

Toda a problemática do texto do prefácio diz respeito ao caráter sistemático ou não da filosofia de Schopenhauer. É controverso dizer se nessa passagem Schopenhauer utiliza a expressão "sistema" como sinônimo de "arquitetônico" e como o contrário de um pensamento "orgânico", ou se a palavra "sistema" indica um conceito superior que poderia ser dividido pelos adjetivos contrários, "arquitetônico" ou "orgânico". Seja como for, "arquitetônico" e "orgânico" são de fato conceitos antagônicos. Tendo em vista que Schopenhauer em diversas passagens, que citaremos abaixo, utiliza-se da expressão "sistema" para caracterizar sua própria filosofia, assumiremos que seu pensamento tem uma forma sistemática e discutiremos até que ponto a filosofia exposta por ele ao longo de sua vida e na forma de livros publicados de fato conseguiu escapar da forma arquitetônica de sistema, negada explicitamente pelo próprio autor no prefácio de 1818. A hipótese que avanço neste texto é que embora defenda uma concepção orgânica de pensamento, a obra de Schopenhauer foi assumindo ao longo dos anos uma forma expositiva cada vez mais arquitetônica. Talvez resida justamente nessa disparidade entre forma e conteúdo a origem de muitas das dificuldades da interpretação de sua filosofia e a caracterização dela como "aporética, antinômica e paradoxal".

Embora a filosofia de Schopenhauer possa ser vista como uma crítica da metafísica tradicional, por negar a possibilidade de hipóstases transcendentes e se basear numa rígida teoria do conhecimento, ele não chega a negar a possibilidade de um conhecimento que dê conta do todo da experiência. A filosofia tem como seu objeto a experiência, mas não essa ou aquela determinada experiência e sim a "experiência em geral", sua possibilidade, seu domínio, seu conteúdo essencial, seus elementos externos e internos, sua forma e matéria. Por essa razão, Schopenhauer irá criticar Kant por sua definição de metafísica como ciência de meros conceitos.

Uma definição de filosofia incomum e indigna, mas que mesmo Kant oferece, é aquela segundo a qual ela seria uma ciência de meros conceitos. Toda a propriedade dos conceitos não consiste em nada senão naquilo que se depositou neles após ter sido solicitado e retirado do conhecimento intuitivo, essa fonte efetiva e inesgotável de toda compreensão. Por isso uma filosofia verdadeira não se deixa entretecer com meros conceitos abstratos; pelo contrário, ela deve ser fundada na observação e experiência, tanto a interna quanto a externa. (P/P II, p. 35). ${ }^{5}$

\footnotetext{
${ }^{44}$ O que Schopenhauer o considera nada mais é do que aquilo "que por muito tempo se procurou sob o nome de filosofia" (Idem).

${ }^{5}$ Ao longo do presente artigo farei algumas citações do importante ensaio Sobre a Filosofia e seu método, texto que abre o segundo volume dos Parerga e Paralipomena de 1851. Para esse texto e alguns outros dos Parerga me valerei das traduções que publiquei pela editora Hedra (Cf. SCHOPENHAUER, 2010 e 2012).
} 
A crítica de Schopenhauer a Kant tem como objetivo a construção de um novo conceito de metafísica, pois se para Kant a finitude da razão impedia que o conhecimento especulativo fosse além de uma fé racional, para Schopenhauer a limitação do saber teórico deve dar lugar a um tipo de experiência capaz de ir além das meras formas da intuição. Essa experiência será localizada no próprio corpo, como chave ao em si do mundo, pois a vontade presente à consciência de si de cada um não está inteiramente submetida às formas de apreensão dos objetos externos. Todavia, o objeto primordial da filosofia é a experiência, embora não como nas demais ciências esta ou aquela experiência particular, mas a experiência em geral, isto é, a forma e o conteúdo de toda experiência possível. Por isso, seu passo inicial consiste em considerar o meio pelo qual se torna possível a experiência, e este meio é para Schopenhauer o intelecto como foco do conhecimento. A philosophia prima será, assim, uma investigação sobre a faculdade de conhecimento, seu alcance e seus limites. Essa investigação se divide, por um lado, pelo estudo das representações intuitivas, primárias, dadas ao entendimento, por isso chamada dianologia. Por outro lado, o estudo das representações secundárias, abstratas, forma a teoria da razão ou lógica. Para Schopenhauer, as intuições empíricas possuem as formas do tempo, do espaço e da causalidade e, embora intelectuais, não são abstratas. Portanto, o domínio do intuitivo teria primazia em relação ao abstrato, que é sempre derivado do primeiro. Se, por um lado, Schopenhauer nega que o conhecimento sensível seja meramente cego e sem conceito, pois ele já conteria a forma da experiência, por outro lado, não haveria conceitos sem sua referência ao empírico,

pois, são justamente os conceitos que adquirem todo significado, todo conteúdo, unicamente por sua referência às representações intuitivas, dos quais foram abstraídos, extraídos, quer dizer formados por abstração de todo inessencial. Portanto, se deles é retirada a base da intuição, são vazios e nulos. As intuições, ao contrário, têm significado imediato e bastante grande (nelas objetiva-se a coisa em si): elas representam-se a si mesmas, enunciam-se por si mesmas, não tem um conteúdo meramente emprestado como os conceitos. (KK/CK, trad. SCHOPENHAUER, 1980, pp. 132-3). ${ }^{6}$

Schopenhauer não diz que a filosofia prescinde completamente de conceitos abstratos. Pelo contrário, essa é sua matéria, embora não sua fonte, pois ela é não uma ciência a partir de conceitos, mas em conceitos ${ }^{7}$. O mérito de Kant consiste em ter reconhecido que os conceitos mais abstratos só permitem um uso na experiência e não na metafísica, isto é, só permitem ligar um fato ao outro (como a causalidade, única categoria aceita por Schopenhauer), não utilizá-lo para além dos fenômenos. É certo, também, que existem intuições puras (como o tempo

\footnotetext{
${ }^{6}$ Para um comentário e uma crítica da interpretação que Schopenhauer faz da filosofia de Kant e da chamada "revolução copernicana", ver Martin Booms (2003, pp. 65-126).

7 "Conceitos universais devem ser de fato o estofo em que a filosofia deposita e conserva o seu conhecimento; contudo, não devem ser a fonte a partir da qual ela o haure: é o terminus ad quem, e não a quo. A filosofia não é, como Kant a define, uma ciência a partir de conceitos, mas ciência em conceitos" (WWV II/MVR II, pp. 49-50). Vale a pena para essa passagem reproduzir o original alemão: "Allgemeine Begriffe sollen zwar der Stoff seyn, in welchen die Philosophie ihre Erkenntniß absetzt und niederlegt; jedoch nicht die Quelle, aus der sie solche schöpft: der terminus ad quem, nicht a quo. Sie ist nicht, wie Kant sie definirt, eine Wissenschaft aus Begriffen, sondern in Begriffen” (SCHOPENHAUER, 1972, vol. III. p. 48).
} 
e o espaço), e até mesmo um conhecimento a priori, que diz respeito apenas à parte formal da experiência. Mas apenas essa parte formal não esgota a experiência; assim, a metafísica, enquanto ciência da experiência em geral, deve basear-se não apenas em conceitos puros a priori, ou na parte formal do conhecimento, mas deve ter uma origem empírica, nos fatos da consciência externa e interna: a metafísica não é apenas dedução das categorias do entendimento, mas decifração da experiência dada. E tal experiência, ainda que tenha no tempo, no espaço e na causalidade suas formas puras, não se esgota aí. Dessa forma, na impossibilidade que a filosofia encontra em se deter em meras determinações abstratas de pensamento, Schopenhauer irá sublinhar, especialmente contra Hegel que a filosofia deve

assim como a arte e a poesia, ter sua fonte na apreensão intuitiva do mundo: também não se deve proceder nela com tanto sangue frio, embora a cabeça tenha de ficar em cima, de tal modo que no final o homem todo não agisse com o coração e a cabeça, ficando inteiramente abalado. Filosofia não é nenhum exemplo de álgebra. Por isso disse Vauvenargues: Les grandes pensées viennent du coeur. (P/P II, pp. 35-6).

A partir dessa caracterização da filosofia, podemos tentar decifrar a afirmação aparentemente enigmática que abre o mesmo ensaio Sobre a filosofia e seu método, presente nos Parerga e Paralipomena (1851) que acabamos de citar: "A base e o solo sobre os quais repousam todos os nossos conhecimentos e ciências é o inexplicável. É a ele que se refere toda explicação, por meio de muitas ou poucas etapas intermediárias, assim como no mar a sonda encontra o fundo, tanto em uma grande quanto em uma pequena profundidade, mas deve, por fim, encontrá-lo por toda a parte. Esse inexplicável cabe à metafísica” (Ibid., p. 29). Ingrata tarefa esta da metafísica: dar conta daquilo que é inexplicável. Por isso, Schopenhauer tentará arrumar um lugar próprio para a filosofia que não se identifica com o da ciência e nem com o da arte, mas estará a meio caminho entre os dois.

Desde o início de sua reflexão filosófica Schopenhauer define a filosofia como um olhar para aquilo que há de mais essencial no mundo, que considera as coisas independentemente de qualquer relação, de seu vir-a-ser, isto é, das mediações que fazem com que elas se tornam o que são. Essa visão da filosofia já está presente na primeira edição de sua obra principal (1818), quando o filósofo afirmava que

o autêntico modo de consideração filosófico do mundo, ou seja, aquele que nos ensina a conhecer a sua essência íntima e, dessa maneira, nos conduz para além do fenômeno, é exatamente aquele que não pergunta "de onde", "para onde", "por que", mas sempre e em toda parte pergunta apenas pelo quê (Das) do mundo; quer dizer, não considera as coisas de acordo com alguma relação, isto é, vindo a ser e perecendo, numa palavra, conforme uma das quatro figuras do princípio de razão, mas diferentemente, tem por objeto precisamente aquilo que permanece após eliminarse o modo de consideração que segue o referido princípio, noutros termos, tem por objeto o ser do mundo sempre igual a si e que aparece em todas as relações, porém sem se submeter a 
estas, numa palavra, as ideias mesmas. A filosofia, como a arte, procede de tal conhecimento. (WWV II/MVR II, p. 323 / trad., p. 317).

Nesse primeiro momento, portanto, a filosofia era definida por Schopenhauer pelo seu parentesco com a arte: ambas teriam em comum o fato de não partirem de relações estabelecidas pelo princípio de razão, mas do conhecimento intuitivo das ideias. Como as ideias são conhecidas por uma espécie de intuição imediata, então a filosofia não pareceria ter a ver com uma atividade puramente racional de conceitos, já que esses são sempre abstrações. Daí sua distância em relação à ciência e sua proximidade com a arte: "Pois a arte não tem a ver como a ciência meramente com a razão, mas com a mais íntima essência do homem [...]. E esse é o caso com minha filosofia; pois ela será filosofia como arte" $\left(\mathrm{HN} / \mathrm{MP}\right.$, vol. I, p. 186) ${ }^{8}$.

A delimitação da tarefa da filosofia indica, porém, uma dificuldade fundamental: ela deve trazer ao conceito aquilo que é da ordem da intuição e do sentimento e, portanto, concreto. Ocorre que o conceito é sempre incapaz de fazer isso, pois a abstração da realidade que é feita pela razão e que origina conceitos nunca preservam a riqueza do mundo intuitivo. Daí o recurso à arte que mostraria, de maneira imediata, o conteúdo concreto da intuição, a saber, as ideias. À medida, porém, que as noções de ideia e conceito vão assumindo um perfil mais definido na obra de Schopenhauer, a filosofia passa a ser menos algo quase idêntico à arte e mais alguma coisa entre a ciência e a arte.

O elemento metafísico [das Metaphysiche], para Schopenhauer, é aquilo que há de mais concreto e não aquilo que é meramente abstraído da experiência. A arte, que é a contemplação das coisas independente do princípio de razão e apreende aquilo que no mundo subsiste fora e independente de toda relação, que é a essência do mundo e o verdadeiro substrato dos fenômenos, participa de um modo de conhecimento próximo ao modo de conhecimento da filosofia. Daí o parentesco profundo entre ambas. Como diz o filósofo, "não é somente a filosofia, mas também as belas artes trabalham para resolver o problema da existência" (WWV II/MVR II, p. 463).

A diferença reside em que, enquanto a arte apresenta uma imagem intuitiva da vida, a filosofia a explica através de conceitos abstratos. Uma oferece, por isso uma satisfação provisória, já que está limitada ao instante da intuição, já a outra uma resposta definitiva, fixada em conceitos 9 . É sobretudo na exposição das ideias que a arte revela seu teor especulativo, pois as ideias não são como os conceitos algo abstraído das intuições, mas a objetivação mesma da essência do mundo. Vale

\footnotetext{
${ }^{8}$ Esse fragmento é de 1814, num período em que o parentesco da filosofia com a arte era constantemente sublinhado pelo autor.

${ }^{9}$ Uma anotação manuscrita do ano de 1817 já expressava de maneira clara o lugar da filosofia: "Na medida em que a filosofia não é um conhecimento segundo o princípio de razão, mas conhecimento da ideia, ela deve ser posta entre as artes; só que ela não expõe a ideia, como as outras artes, como ideia, isto é, intuitivamente, mas in abstracto. Mas como todo assentar em conceitos é um saber; ela é então também uma ciência: de fato ela é uma mescla [Mittleres] de arte e ciência, ou antes algo que une a ambas". (HN/MP, vol. I, p. 482). Cf. KOSSLER, 1990, p. 155.
} 
a pena citar uma passagem que nos oferece com clareza a concepção do filósofo sobre o lugar da filosofia em relação à ciência e à arte:

A filosofia ou metafísica, como teoria da consciência e seu conteúdo em geral, ou da totalidade da experiência como tal, não entra na relação [das ciências particulares]; pois ela não segue a consideração exigida pelo princípio de razão, mas antes toma esse mesmo como objeto. Ela deve ser vista como o baixo contínuo de todas as ciências, é porém, de um tipo mais elevado do que essas e aparentada com a arte quase tanto quanto com a ciência. (WWV II/MVR II, p. 40). ${ }^{10}$

Tudo estaria perfeito se não fosse a incapacidade da razão de expor o rico conteúdo da experiência imediata. Essa incapacidade não é responsável apenas pela falta de certeza apodítica da metafísica, mas também pelo seu caráter quase hipotético. Na verdade, essas limitações que Schopenhauer assinala para sua própria filosofia se deve ao menos a três fatores: primeiro, o caráter secundário da razão, sempre dependente de uma intuição e por isso incapaz de se mover sem qualquer referência à experiência; em segundo lugar, a imperfeição metafísica (essencial) do intelecto, mero instrumento da vontade, feito para a execução de seus fins e não originariamente destinado ao conhecimento puro das coisas; e por último, o filósofo reconhece que o caminho que leva da intuição da vontade na consciência de si ao reconhecimento da vontade no mundo é apenas uma visada inadequada para resolver todos os mistérios do mundo: "também a percepção interna que nós temos de nossa própria vontade, de modo algum oferece um conhecimento completo e adequado da coisa em si” (WWV II/MVR II, p. 220). É verdade que o contato que temos com os atos de nossa própria vontade é o único a nós imediatamente conhecido e está, portanto, mais livre das formas da representação que todos os outros objetos da consciência. Mesmo assim, ele ainda é mediatizado, não apenas por manter a relação sujeito e objeto (algo que conhece - a consciência de si, se relaciona, por meio do intelecto, com algo a ser conhecido), mas ainda por manter intocada a forma do tempo, enquanto forma do sentido interno na consciência de si. O que a torna mais imediata que qualquer outra intuição é o fato de estar livre da forma do espaço e de "toda forma da causalidade mediatizada pela intuição sensível" (Ibid.). Por isso, continua o filósofo, "nesse conhecimento a coisa em si despojou-se em grande parte de seus véus, mas não apareceu ainda inteiramente nua (Ibid.)".

Se é assim, ou seja, se a filosofia de Schopenhauer, entendida como metafísica fundada na experiência, isto é, na experiência imediata do sujeito, é

\footnotetext{
${ }^{10}$ Essa concepção da filosofia, como tão aparentada com a ciência quanto com a arte por um lado, e por outro como superior a ambas, nos parece ser a visão definitiva do filósofo, ainda que outras passagens possam levar a outras interpretações. Sobre isso nos filiamos à interpretação de R. Malter (1991, p. 37): "Se Schopenhauer frequentemente reforça a proximidade da filosofia com a arte, isso não quer dizer que exista nele uma tendência a negar os momentos que a filosofia tem em comum com a ciência. Está claro a partir da concepção de conjunto ainda a ser explicada do pensamento de Schopenhauer, porque a filosofia e a arte estão mais próximas uma da outra do que a filosofia e a ciência: o interesse de Schopenhauer recai muito menos sobre o lado formal-metodológico do pensar filosófico do que sobre o lado conteudístico [inhaltlich]. É verdade que a questão pelo como da compreensão da essência do mundo tematizado no mundo como vontade e representação poder ser comunicada in abstracto, é de fundamental importância para Schopenhauer, mas ainda mais fundamental é seu interesse na essencialidade a ser retratada do mundo".
} 
baseada numa certeza apenas plausível, então não surpreenderá a forma expositiva que essa filosofia assumirá. Não apenas a certeza apodítica será abandonada; a própria ideia de "sistema" é relativizada, o que dará lugar à forma ensaística e aforismática que a filosofia de Schopenhauer apenas esboçará. E principalmente, o conhecimento de um princípio ou fundamento absoluto é objeto não apenas de uma crítica gnosiológica, mas também de uma recusa.

Como vimos no início, a dificuldade da forma expositiva de sua filosofia é colocada por Schopenhauer com toda a clareza no prefácio à primeira edição de sua obra principal. A noção do único pensamento de certo modo relativiza a noção de sistema, e a dessemelhança entre seu conteúdo e sua exposição é justamente sintoma disso.

Talvez essa clivagem conscientemente assumida seja uma das fontes das célebres "aporias, contradições e paradoxos" da filosofia de Schopenhauer. O "sistema" nunca fecha, pois justamente a forma expositiva necessariamente sistemática, porque conceitual, que ele possui, nunca alcançará aquele "espelhamento" que constitui sua tarefa. Ciente dessa dificuldade e sem contradizer sua intuição originalmente orgânica, Schopenhauer não verá dificuldade de referirse à sua obra como "sistemática" e para convencer-se disso basta mencionar aqui alguns exemplos, mencionados como elementos para uma futura reconstrução sistemática da filosofia de Schopenhauer.

$\mathrm{Na}$ primeira edição de sua obra principal, Schopenhauer não dividiu seu texto em parágrafos [\$§] como passou a fazer apenas a partir da segunda edição de 1844. O segundo volume é estruturado em capítulo que fazem referência a esses parágrafos e estabelecem assim uma relação sistemática com os mesmos. O mesmo acontecerá no segundo volume dos Parerga e Paralipomena, onde em seu curto prefácio Schopenhauer assume explicitamente a noção de sistema:

Esses escritos complementares acessórios de minhas obras mais importantes, sistemáticas consistem em parte em alguns tratados sobre temas particulares bem variados, em parte em pensamentos específicos sobre objetos ainda mais variados. Tudo isso é reunido aqui porque em razão de sua matéria parte desses elementos não poderiam encontrar seu lugar nas obras sistemáticas, enquanto a outra parte está aqui apenas porque vieram à lume muito tarde para encontrar seu lugar em tais obras. (P/P I, p. 5).

Poderíamos ainda mencionar uma passagem do final do último capítulo dos Complementos ao segundo livro que menciona a ideia de uma "arquitetônica". Trata-se do capítulo 28 chamado "Característica da Vontade de viver" em que Schopenhauer menciona a ligação dessa temática com o que é tratado no quarto livro, mas dada sua arquitetônica pré-estabelecida, antes de tratar da ética caberia passar à estética ${ }^{11}$. E se quisermos mencionar um texto mais antigo, vale dizer que já na dissertação de 1813 Sobre a quadrupla Raiz do Princípio de Razão Suficiente,

11 "Eu somente preciso bem chamar a atenção para o fato de que as considerações com as quais aqui encerro o segundo livro já apontam contundentemente para o grave tema do quarto livro, sim, levariam diretamente a ele se a minha arquitetônica não fizesse necessário que primeiro eu inserisse entre os dois, como uma segunda consideração do mundo como representação, o nosso terceiro livro com seu jovial conteúdo, cuja conclusão, no entanto, de novo aponta para o mesmo grave tema" (WWV II/MVR II, p. 432). 
Schopenhauer se refere a uma apresentação alternativa das formas do princípio de razão que ao invés de serem arroladas segundo uma ordem intuitiva, poderia ser exposta numa forma sistemática: assim, ao invés da ordem de apresentação das quatro formas do princípio de razão, tais como exposta na dissertação de 1813, a saber: a) princípio de razão do devir, que rege as representações intuitivas dadas ao entendimento na experiência empírica; b) princípio de razão do conhecer, que rege as representações abstratas, os conceitos, dados pela razão; c) princípio de razão do ser, que é dado pelas formas a priori da intuição, o tempo e o espaço; d) princípio de razão do agir humano, a motivação; teríamos, ao invés dessa, uma exposição sistemática que traria a seguinte ordem:

primeiro deve expor-se o princípio de razão do ser, e deste, seu primeiro emprego no tempo, como o mais simples e que contém o esquema de todos os demais, como o protótipo de toda finitude; então, depois de expor a razão do ser também no espaço, a lei de causalidade, da qual se segue a motivação, e por último o princípio de razão suficiente do conhecer, uma vez que os outros se baseiam em representações imediatas e este em representações de representações. (SG/PR, In: SCHOPENHAUER, 1972, vol. I, p. $150)^{12}$.

Por fim, como expressão do caráter sistemático de sua filosofia, citamos outro texto do ensaio Sobre a filosofia e seu método que ao mencionar a questão da divisão das matérias na filosofia parece apresentar a visão madura e talvez definitiva sobre a estrutura sistemática de sua obra. Por conta de sua importância e apesar de longa, a citamos na íntegra:

A filosofia tem como seu objeto a experiência, é verdade, mas não como as outras ciências, essa ou aquela experiência determinada, mas a experiência mesmo em geral e como tal, segundo sua possibilidade, seu domínio, seu conteúdo essencial, seus elementos internos e externos, sua forma e sua matéria. Por conseguinte, a filosofia deve ter uma base empírica e não ser entretecida a partir de conceitos puros e abstratos, como eu expliquei de maneira pormenorizada no capítulo 17 do segundo volume de minha obra principal (págs. 180-185) e também resumi rapidamente acima no parágrafo 9. Por aquilo que se declarou ser seu tema, resulta que a primeira coisa que ela tem que considerar é o medium pelo qual a experiência em geral se apresenta a si mesma, ao lado de sua forma e natureza. Esse medium é a representação, o conhecimento, portanto o intelecto. Dessa forma, toda filosofia deve começar com uma investigação sobre a faculdade de conhecimento, suas formas e leis, assim como de sua validade e de seus limites. Uma tal investigação será a philosophia prima. Ela se divide, de um lado, na consideração das representações primárias, isto é, intuitivas, parte que recebe o nome de Dianologia ou teoria do entendimento; e de outro, na consideração das representações secundárias, isto é, abstratas, assim como da ordenação de sua manipulação, formando assim a

\footnotetext{
${ }^{12}$ Essa tese é sustentada por Schopenhauer justamente num parágrafo da dissertação denominado "ordenação sistemática" ( $\$ 52$ da primeira edição e $\$ 46$ da segunda): "A ordem em que expus as diversas formas do princípio de razão suficiente não é a sistemática, mas foi escolhida tendo em vista a mera clareza, para começar com a mais conhecida e que necessita menos das demais" (Idem, Ibidem).
} 
lógica ou a teoria da razão. Essa parte geral compreende, ou melhor, substitui ao mesmo tempo aquilo que outrora se chamava Ontologia, que compunha a teoria das propriedades mais universais e essenciais das coisas em geral enquanto tais. Pois se considera como propriedades das coisas em si mesmas o que somente pertence a elas em consequência da forma e da natureza de nossas faculdades representativas, já que todos os seres que essas apreendem devem se exibir de acordo com a forma e natureza da nossa faculdade representativa e, por isso, deve trazer em si certas propriedades comuns a todas elas. Isso se compara ao ato de atribuir uma cor aos objetos a partir da lente pela qual as vemos.

A filosofia que se segue de tal investigação é a metafísica em sentido estrito, pois ela não apenas reconhece aquilo que existe, a natureza, a ordena e a considera em seu nexo, mas também a apreende como um fenômeno dado, mas de alguma maneira determinado, na qual se apresenta um ser dela mesma diferente, que seria então a coisa em si. Esta última é aquilo que ela busca conhecer mais de perto: os meios para isso são, em parte, a combinação da experiência externa com a interna e, em parte, a conquista de uma compreensão do fenômeno em seu conjunto, por meio da descoberta de seu sentido e de sua conexão - o que pode ser comparado à leitura dos caracteres misteriosos de um escrito desconhecido. Nesse caminho, a filosofia chega, a partir da aparência, àquilo que aparece [Erscheinende], àquilo que está

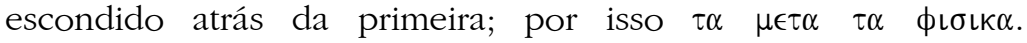
Consequentemente, ela se divide em três partes:

Metafísica da natureza

Metafísica do belo

Metafísica dos costumes

A dedução dessa divisão pressupõe já a metafísica. Essa indica a coisa em si, a essência íntima e última do fenômeno como presente em nossa vontade; por isso será investigada, depois da consideração de como ela se apresenta na natureza externa, sua manifestação imediata e bem diferente em nosso íntimo, donde surge a metafísica dos costumes. Antes disso, porém, será tomada em consideração a compreensão mais completa e pura de sua manifestação objetiva e exterior, que nos é oferecida pela metafísica do belo. (P/P II, p. 46-48).

A partir dessa estrutura sistemática poderão surgir fragmentos de pensamento que complementam o sistema. O sistema, porém, não é um único sistema, como pensado por autores como Hegel e Schelling, mas a visão de mundo de Schopenhauer apresentada de forma sistemática. Como qualquer outra visão de mundo ela não pretende esgotar todo o conhecimento possível e reconhece claramente suas limitações. Para aproximar-se da inesgotável fonte de conhecimentos que é a experiência não deve ser dispensada a fina observação e a espirituosa compreensão, constitutiva dos grandes gênios. Essa genialidade é aquela que se pode apreciar nos "escritos de espíritos privilegiados como Teofrastro, Montaigne, La Rochefoucauld, Labruyère, Helvétius, Chamfort, Addison, Shaftesbury, Shenstone, Lichtenberg entre outros. Mas isso não se deve buscar nem aturar nos compêndios de professores de filosofia sem espírito e por isso hostis a ele" (Ibid., p. 49). 


\section{REFERÊNCIAS BIBLIOGRÁFICAS}

BOOMS, Martin. Aporie und Subjekt. Die erkenntnistheoretische Entfaltungslogik der Philosophie Schopenhauers. Würzburg: Königshausen und Neumann, 2003.

BRANDÃO, Eduardo. O Conceito de Matéria na obra de Schopenhauer. Tese de Doutorado. São Paulo: Universidade de São Paulo, 2003

A concepção de matéria em Schopenhauer e o Absoluto. In: SALLES, João C. (Org.). Schopenhauer e o Idealismo alemão. Salvador: Quarteto, 2004. p. 45-57.

CACCIOlA, Maria L. M. O. A Crítica da Razão no Pensamento de Schopenhauer. Dissertação de mestrado. São Paulo: Universidade de São Paulo, 1981.

. Schopenhauer e a Questão do Dogmatismo. São Paulo: Edusp, 1994.

. O intuitivo e o abstrato na filosofia de Schopenhauer. In: SALLES, J. C.

(Org.). Schopenhauer e o Idealismo alemão. Salvador: Quarteto, 2004. p. 169-186.

GUÉROUlT, Martial. Études de Philosophie allemande. New York: Hildesheim, 1977.

HORSTMANN, Rolf-Peter. Die Grenzen der Vernunft. Eine Untersuchung zu Zielen und Motiven des Deutschen Idealismus. $3^{\underline{a}}$ ed. Frankfurt am Main: Vittorio Klostermann, 2004.

KANT, Immanuel. Prolegómenos a toda a metafísica futura. Trad. Artur Morão. Lisboa: Edições 70, 1987.

Crítica da Razão Pura. Trad. de Manuela Pinto dos Santos e Alexandre F. Morujão. Lisboa: Ed. Calouste Gulbenkian, 1993.

KOSSLER, Matthias. Substantielles Wissen und subjektives Handeln: dargestellt in einem Vergleich von Schopenhauer un Hegel. Frankfurt a. M., Bern, Paris, New York: Lang, 1990.

A única intuição - o único pensamento: Sobre a questão do sistema em Fichte e em Schopenhauer. Revista Dois Pontos. Curitiba, São Carlos, v. 4, n. 1, p. 153-173, abril de 2007.

LEBRUN, Gérard. Kant e o Fim da Metafísica. Trad. de Carlos Aberto Ribeiro de Moura. São Paulo: Martins Fontes, 1993.

MALTER, Rudolf. Arthur Schopenhauer. Transzendentalphilosophie und Metaphysik des Willens. Stuttgart-Bad Cannstatt: Frommann-holzboog, 1991.

SCHOPENHAUER, Arthur. __ Sämtliche Werke. Editadas e comentadas criticamente por Arthur Hübscher. Wiesbaden: F. A. Brockhaus, 1972, 7 vols.

Crítica da Filosofia Kantiana. Tradução de Maria Lúcia Cacciola. Coleção "Os Pensadores". 2ª ed. São Paulo: Abril Cultural, 1980.

Der Handschriftliche Nachlass. 5 vols. HÜBSCHER, Arthur (Ed.). Munique: Deutscher Taschenbuch Verlag, 1985.

Parerga und Paralipomena. 2 vols. Zurique: Haffmans, 1988. 
Sobre o Fundamento da Moral. Tradução de Maria Lúcia Cacciola. São Paulo: Martins Fontes, 1995.

Sobre a filosofia e seu método (Capítulos 1 - 7 de Parerga e Paralipomena de Arthur Schopenhauer). Organização e tradução de Flamarion C. Ramos. São Paulo: Hedra, 2010.

Sobre a ética. (Capítulos 8 - 15 de Parerga e Paralipomena de Arthur Schopenhauer). Organização e tradução de Flamarion C. Ramos. São Paulo: Hedra, 2012.

O Mundo como Vontade e como Representação. Primeiro tomo. $2^{\underline{a}}$ ed. Tradução de Jair Barboza. São Paulo: Unesp, 2015a.

O Mundo como Vontade e como Representação. Segundo tomo: Suplementos aos quatro livros do primeiro tomo Tradução de Jair Barboza. São Paulo: Unesp, 2015b.

Recebido em: 31-07-2018

Aceito para publicação em: 02-11-18 